\title{
Synthesis and Characterization of New Organosoluble and Thermally Stable Poly(thioether-amide)s Bearing Pyridine Subunit in the Main Chain
}

\author{
Esmael Rostami, Maryam Bagherzadeh, Tahereh Alinassab, Maryam Mohammadpour, \\ Masume Zangooei, Mahmood Feraidooni, Fatemeh Tavazo, and Zahra Keshavarz
}

Department of Chemistry, Payame Noor University, P.O. Box 19395-3697, Tehran, Iran

Correspondence should be addressed to Esmael Rostami; esmrostami@yahoo.com

Received 11 January 2014; Accepted 3 February 2014; Published 27 April 2014

Academic Editors: H.-L. Chen, W. S. Chow, and A. V. Raghu

Copyright (C) 2014 Esmael Rostami et al. This is an open access article distributed under the Creative Commons Attribution License, which permits unrestricted use, distribution, and reproduction in any medium, provided the original work is properly cited.

\begin{abstract}
We report the synthesis of new polyamides containing 2,6-bis(2-thio-2-(4-carboxyphenyl)-1-oxo)pyridine subunit, under microwave irradiation using Yamasaki phosphorylation method. The solubility, thermal behavior, and viscosity of polyamides were evaluated. The structures of polymers have been characterized using IR and ${ }^{1} \mathrm{H}$ NMR spectroscopy. These polyamides showed good solubility, viscosity, high thermal stability, and glass transition temperatures. Their viscosities and glass transition temperatures are in the range of $0.63-0.88$ and $223-295^{\circ} \mathrm{C}$, respectively. Thermal stabilities for $10 \%$ weight loss (T10) are $137-173^{\circ} \mathrm{C}$ and for $50 \%$ weight loss (T50) are in the range of $483-523^{\circ} \mathrm{C}$. The study of surface morphology showed particle and amorphous structures.
\end{abstract}

\section{Introduction}

Aromatic polyamides (aramides) explore high thermal stability, good chemical resistance, excellent mechanical properties, and a series of reliable properties that have broad applications in many areas of research and engineering [14]. However, all of these polymers have the main problem of being difficult to process and of fabrication because of their infusibility and poor solubility in common organic solvents. The reasons are strong interchain forces and interactions, inherent macromolecular rigidity, or crystallinity.

There has been an increased attention in the preparation of polyamides with different substituents or structural irregularities to improve their process ability without lowering their other desired properties. These studies include entering flexible adducts into the polymer main chain [5-7], replacing symmetrical aromatic rings by unsymmetrical ones [8-10], introducing bulky and reliable pendent groups to minimize crystallization [11-15], and forming a noncoplanar and nonsymmetrical structure [16-18].

Since the first published reports on the use of microwave irradiation to improve chemical transformations by Gedye et al. in 1986 [19], a large number of research papers have been published in this active field, referred to as microwaveassisted organic synthesis (MAOS) [20, 21]. Microwave heating compared to conventional heating procedures indicated that it could reduce reaction times, increase product yields, and enhance product purities by reducing byproducts. The advantages of this efficient technology have also been explored in the context of multistep total synthesis [22], medicinal chemistry, and drug discovery [23]. Also, these methods were used in a series of fields such as polymer synthesis [24], material sciences [25], nanotechnology [26], and biochemical processes [27]. The use of microwave irradiation in polymer chemistry has thus become such a popular technique that a series of chemists will probably use microwave energy to heat chemical reactions on a laboratory scale to prepare a large number of polymers [28]. This efficient method of organic synthesis has been used in a large number of polymer reactions such as step-growth polymerization for the preparation and synthesis of polyamides [29], polyimides [30], poly(amide-imide)s [31], polyesters [32], polyurea, and polythiourea [33]. Also, chain growth polymerization under microwave (MW) irradiation has been applied for the synthesis of a large number of polymers and macromolecules [34]. 
<smiles>CCCCN(C)C(C)(C)CC(=O)Nc1cccc(NC(=O)CCl)n1</smiles>

3<smiles>CC(C)(C)C(=O)CCC(=O)O</smiles>

SCHEME 1: Synthesis of monomer (5, PDA).

In this study, new poly(thioether-amide)s containing pyridine [35] thioether-amide subunits in the main chain were synthesized under microwave irradiation and characterized. It has been demonstrated that they are soluble in a series of common organic solvents and showed thermal resistance. Surface morphology of these polymers was studied using scanning electron microscopy (SEM).

\section{Experimental}

2.1. Materials, Instruments, and Physical Measurements. The reactions for the synthesis of monomer were carried out in an efficient hood. All the materials were purchased from Merck, Fluka, Across Organics, and Aldrich chemical companies. N-Methyl-2-pyrrolidinone (NMP, Merck) and pyridine (Py, Merck) were purified by distillation under reduced pressure over calcium hydride and stored over $4 \mathrm{~A}^{\circ}$ molecular sieves. Triphenyl phosphite (TPP, Merck) was purified by fractional distillation under vacuum. Reagent grade aromatic diamines (Aldrich) including 2,6-pyridine diamine (PYDA, 6), 1,3phenylenediamine (PHDA, 7), 3,3'-diaminodiphenylsulfone (8), and 4,4' -diaminodiphenylsulfone (9) were recrystallized from ethanol. The melting points (uncorrected) were measured with a Barnstead Electrothermal engineering LTD 9100 apparatus. Elemental analysis was performed by a $\mathrm{CHN}-$ O- Rapid Heraeus elemental analyzer. FT-IR spectra were recorded in potassium bromide pellets on a Bruker apparatus. The ${ }^{1} \mathrm{H}$ NMR and ${ }^{13} \mathrm{C}$ NMR spectra were obtained using Bruker Avance DRX $500 \mathrm{MHz}$ apparatus and mass spectra were obtained with Shimadzu GC-MS-QP 1100 EX model. Scanning electron micrograph (SEM) images were obtained using a XL30 (Philips) apparatus. The MicroSYNTH system of Milestone which is a multimode platform and is equipped with a magnetic stirring plate was used for the microwave synthesis. Inherent viscosities $\left(\eta_{\text {inh }}=\ln \eta r / c\right.$ at a concentration of $0.5 \mathrm{~g} \mathrm{dL}^{-1}$ ) were measured with an Ubbelohde suspended-level viscometer at $30^{\circ} \mathrm{C}$ using DMSO as solvent. Thermogravimetric analysis (TGA) was recorded on a V 5.1A DuPont 2000 system under argon atmosphere at a heating rate of $10^{\circ} \mathrm{C} \mathrm{Min.}^{-1}$ and differential scanning calorimetry (DSC) recorded on a V 4.OB DuPont 2000 system under argon atmosphere at a heating rate of $10^{\circ} \mathrm{C} \mathrm{Min.}^{-1}$.

2.2. Synthesis of 2,6-Bis (2-Thio-2-(4-phenylcarboxy)-1-oxo) pyridine $(\boldsymbol{P D A}, 5)$. To DMF $(30 \mathrm{~mL})$ were added 2,6-bis (2-chloro-1-oxo)pyridine [36] (3, $1 \mathrm{mmol}, 0.259 \mathrm{~g}), \mathrm{K}_{2} \mathrm{CO}_{3}$ ( $4 \mathrm{mmol}, 0.56 \mathrm{~g})$, and thiosalicylic acid (4,2 mmol, $0.30 \mathrm{~g})$ at room temperature as shown in Scheme 1. The reaction mixture was stirred at room temperature for $24 \mathrm{~h}$. After completion of the reaction (monitored by TLC), water was added and the reaction mixture was neutralized with $\mathrm{HCl}$ solution. After standing for $2 \mathrm{~h}$, the resulting precipitate was filtered and recrystallized in ethanol to obtain diacid (5) in $94 \%$ yield and melting point of $223-224^{\circ} \mathrm{C}$. IR $(\mathrm{KBr}) \nu \mathrm{cm}^{-1}$ was $3356,3078,2898,2363,1697,1646,1446,1146$, and $732 .{ }^{1} \mathrm{H}$ NMR $\left(500 \mathrm{MHz}, \mathrm{DMSO}-\mathrm{d}_{6}\right) \delta$ was $3.99(\mathrm{~s}, 4 \mathrm{H}), 7.22-7.25(\mathrm{~m}$, 2H), 7.49-7.53 (m, 4H), 7.73-7.78 (m, 3H), 9.92 (dd, $J=1,8 \mathrm{~Hz}$, $2 \mathrm{H}$ ), and $10.36(\mathrm{~s}, 2 \mathrm{H}) \mathrm{ppm} .{ }^{13} \mathrm{C}$ NMR $(125 \mathrm{MHz}, \mathrm{DMSO}-$ $\left.\mathrm{d}_{6}\right) \delta$ was $168.65,168.30,150.84,141.33,141.27,133.36,131.91$, $128.64,126.40,125.15,110.04$, and $37.05 \mathrm{ppm}$. MS (EI) $\mathrm{m} / z$ (relative intensity \%) was $497[\mathrm{M}]^{+}(6 \%), 461(12), 285$ (24), 150 (73), 109 (100), 82 (76), and 39 (71). Analytical calculation for $\mathrm{C}_{23} \mathrm{H}_{19} \mathrm{~N}_{3} \mathrm{O}_{6} \mathrm{~S}_{2}(M=497.54)$ was $\mathrm{C}, 55.52 \%$; $\mathrm{H}, 3.85 \%$; $\mathrm{N}$, 8.45 and found $\mathrm{C}, 55.58 \% ; \mathrm{H}, 3.81 \%$; N, $8.57 \%$. 
<smiles></smiles><smiles>Cc1cccc(C)n1</smiles>

10<smiles>Cc1cccc(C)c1</smiles>

11<smiles>Cc1cccc(S(=O)(=O)c2cccc(C)c2)c1</smiles>

12

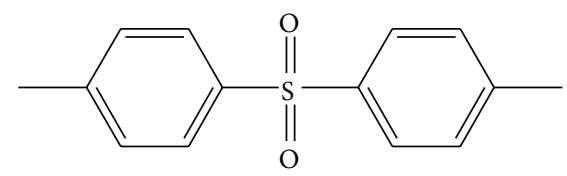

13

SCHEme 2: Synthesis of polyamides (10-13).

2.3. Synthesis of Polyamides. Polyamides were synthesized through the phosphorylation reaction of 2,6-bis(2-thio-2(4-phenylcarboxy)-1-oxo)pyridine (5, PDA) with various diamines as shown in Scheme 2. A typical example for the preparation of polyamides is given. A mixture of 5
( $1 \mathrm{mmol}, 0.498 \mathrm{~g}$ ), 1,3-phenylenediamine ( $1 \mathrm{mmol}, 0.11 \mathrm{~g}$ ), $0.3 \mathrm{~g}$ of $\mathrm{CaCl}_{2}, 0.6 \mathrm{~mL}$ of TPP, $0.5 \mathrm{~mL}$ of pyridine, and $4 \mathrm{~mL}$ of NMP was added to the quartz tube and irradiated under microwave conditions in $600 \mathrm{~W}$ for $9 \mathrm{Min} .(3 \times 3 \mathrm{Min}$. $)$ and for the rest time of $10 \mathrm{Min}$. $(2 \times 5 \mathrm{Min}$. $)$. After cooling to 
room temperature, the resulting viscose reaction mixture was poured into $300 \mathrm{~mL}$ of boiling methanol. The resulting crude product was precipitated and then filtered. The resulting polymer was washed with hot methanol $(50 \mathrm{~mL})$, hot water (twice, $50 \mathrm{~mL}$ ), and then hot methanol $(50 \mathrm{~mL})$, respectively, and dried under vacuum at $100^{\circ} \mathrm{C}$ overnight. The yields were almost quantitative. Spectral data, thermal properties, viscosity, and solubility of these polyamides were presented in the tables and figures.

\section{Results and Discussion}

In this research work, we wish to report the synthesis and characterization of polyamides, which were obtained from the reaction of a new monomer (5, PDA), containing 2,6-bis(2-thio-2-(4-phenylcarboxy)-1-oxo)pyridine subunit, and aromatic diamines under microwave irradiation. Dichloroamide (3) was readily prepared by using a published method, with some modifications, from the reaction of $\mathbf{1}$ and chloroacetyl chloride [35]. Diacid monomer (5) was prepared by the reaction of 3 and thiosalicylic acid (4) in DMF at room temperature. The IR spectrum of diacid (5, PDA) is presented in Figure 1. The polymerizations were carried out via Yamasaki phosphorylation reaction, by the reaction of diacid (5) and different diamines in the presence of triphenyl phosphite (TPP), pyridine (Py), N-methylpyrrolidinone (NMP), and calcium chloride $\left(\mathrm{CaCl}_{2}\right)$, under microwave irradiation almost in quantitative yields (Table 1). Polymers were precipitated in boiling methanol and washed with hot water and methanol, respectively. The inherent viscosities and the yields of polyamides were revealed in Table 1 . The viscosities of polyamides were measured in DMSO at $30^{\circ} \mathrm{C}$ and are in the range of $0.63-0.88$ (Table 1). The structures of polymers were fully characterized by their ${ }^{1} \mathrm{H}$ NMR and IR spectra (Table 2). The IR spectrum of polyamide 13 (PPS) appears in Figure 2 and shows good agreement between absorptions and the corresponding structure (Table 2).

The thermal stability of polyamides was studied by thermogravimetric analysis (TGA) and differential scanning calorimetry (DSC) methods in a wide range of temperature. The entire polymers showed good thermal stability; the results appear in Table 3 and curves are displayed in Figure 3. Glass transition temperature $\left(T_{g}\right)$ measurements were carried out by use of a differential scanning calorimetry (DSC) and were in the range of $223-295^{\circ} \mathrm{C}$. The results appear in Table 3. According to the effects of diamine structure on the thermal behaviour, the insertion of a sulfone group into the diamine structure decreases the overall flexibility of the polymer chains and increased the $T_{g}$ value. The polymers containing diamines with no flexible groups (such as 1,4and 1,3-phenylenediamine and 2,6-pyridinediamine derivatives) have high $T_{g}$, possibly due to a less flexible polymer backbone.

The thermal stability was measured by thermogravimetric analysis (TGA) and shown that polymers are well thermally stable, their decomposition at argon atmosphere for temperature of $10 \%$ weight loss $T$ (10) was in the range of $137-173^{\circ} \mathrm{C}$, and the temperature of $50 \%$ weight loss $T$ (50) was

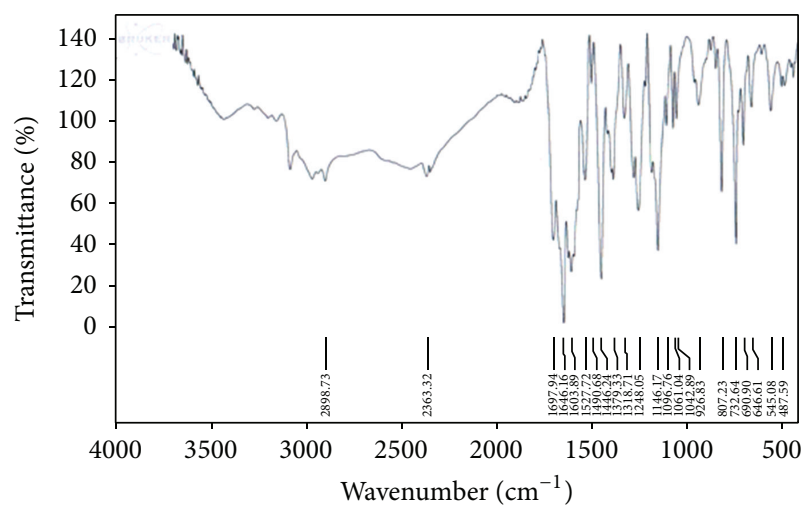

FIGURE 1: FT-IR spectrum of diacid (5, PDA).

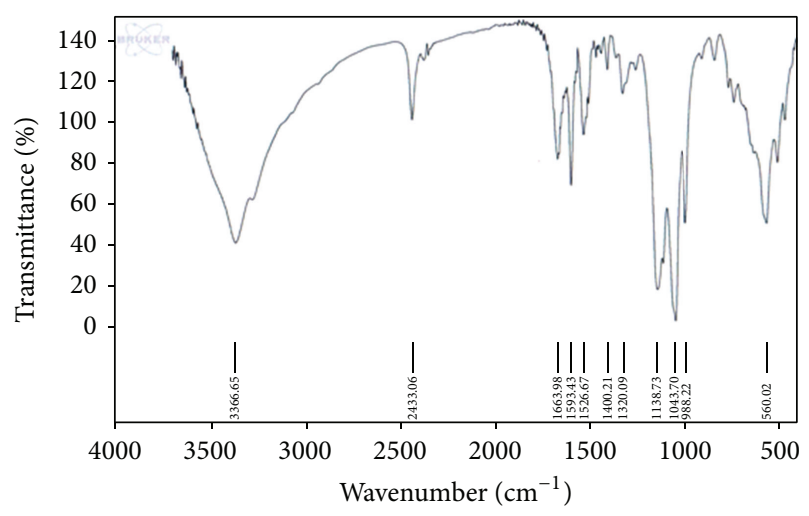

FIGURE 2: FT-IR spectrum of polyamide (13, PPS).

TABLE 1: Inherent viscosity and the yields of polyamides.

\begin{tabular}{lcc}
\hline Polymer & Yield (\%) & $\eta_{\text {Inh }}(\mathrm{g} / \mathrm{dL})^{\mathrm{a}}$ \\
\hline PPY (10) & 94 & 0.75 \\
PPH (11) & 92 & 0.63 \\
PMS (12) & 96 & 0.82 \\
PPS (13) & 98 & 0.88 \\
\hline
\end{tabular}

${ }^{\mathrm{a}}$ Measured at a polymer concentration of $0.5 \mathrm{~g} / \mathrm{dL}$ in DMSO solvent at $30^{\circ} \mathrm{C}$.

in the range of $483-523^{\circ} \mathrm{C}$. The polymers decomposition temperatures for various percent of decomposition and char yield at $550^{\circ} \mathrm{C}$ for all polymers are presented in Table 3 . According to the data obtained by thermal stability measurements, the incorporation of sulfone units into the polymers backbone enhanced the thermal stability.

The solubility behavior of polyamides is investigated qualitatively in a series of organic solvents such as N-methylpyrrolidinone (NMP), N,N-dimethylformamide (DMF), tetrahydrofuran (THF), dimethyl sulfoxide (DMSO), N,Ndimethylacetamide (DMAc), and $m$-cresol, and the results are summarized in Table 4 . All the polymers showed reliable solubility in polar organic solvents. This might be due to the presence of aromatic and methylene subunits and the decrease of intermolecular and intramolecular hydrogen bonding. Amine, amide, and thioether units increase the intermolecular and intramolecular hydrogen bonding and 
TABLE 2: Spectral data of polymers.

\begin{tabular}{|c|c|c|}
\hline Polymer & $\operatorname{IR}\left(\nu \mathrm{cm}^{-1}\right)$ & ${ }^{1} \mathrm{H}$ NMR $\left(500 \mathrm{MHz}\right.$, DMSO- $\left.\mathrm{d}_{6}\right): \delta(\mathrm{ppm})$ \\
\hline PPY (10) & $3358,3072,2897,2361,1698,1661,1647,1445,1149$, and 733 & $\begin{array}{c}4.69(\mathrm{~s}, 4 \mathrm{H}), 7.41(\mathrm{~d}, J=9 \mathrm{~Hz}, 2 \mathrm{H}), 7.54-7.57(\mathrm{~m}, 3 \mathrm{H}) \\
7.68-7.72(\mathrm{~m}, 3 \mathrm{H}), 7.93(\mathrm{~d}, J=8.5 \mathrm{~Hz}, 2 \mathrm{H}), 7.99(\mathrm{~d}, J=7.5 \mathrm{~Hz} \\
2 \mathrm{H}), 8.30(\mathrm{~d}, J=8.5 \mathrm{~Hz}, 2 \mathrm{H}), 10.42(\mathrm{~s}, 2 \mathrm{H}) \text {, and } 10.44(\mathrm{~s}, 2 \mathrm{H})\end{array}$ \\
\hline PPH (11) & $3376,3145,2983,2491,1683$, and 1115 & $\begin{array}{c}4.37(\mathrm{~s}, 4 \mathrm{H}), 5.98(\mathrm{~m}, 1 \mathrm{H}), 6.15(\mathrm{~m}, 2 \mathrm{H}), 6.97(\mathrm{~m}, 1 \mathrm{H}) \\
7.28-7.33(\mathrm{~m}, 2 \mathrm{H}), 7.56-7.62(\mathrm{~m}, 4 \mathrm{H}), 7.78-7.82(\mathrm{~m}, 3 \mathrm{H}), 9.95 \\
(\mathrm{dd}, J=1,8 \mathrm{~Hz}, 2 \mathrm{H}), 10.38(\mathrm{~s}, 2 \mathrm{H}) \text {, and } 10.39(\mathrm{~s}, 2 \mathrm{H})\end{array}$ \\
\hline PMS (12) & $\begin{array}{c}3481,3363,3224,2983,2431,1698,1667,1622,1595,1137 \text {, and } \\
1045\end{array}$ & $\begin{array}{c}3.99(\mathrm{~s}, 4 \mathrm{H}), 6.85-6.87(\mathrm{~m}, 2 \mathrm{H}), 7.08-7.09(\mathrm{~m}, 2 \mathrm{H}), 7.18-7.20 \\
(\mathrm{~m}, 2 \mathrm{H}), 7.28-7.31(\mathrm{~m}, 2 \mathrm{H}), 7.61-7.63(\mathrm{~m}, 4 \mathrm{H}), 7.79-7.81(\mathrm{~m}, \\
3 \mathrm{H}), 9.93(\mathrm{dd}, J=1,8 \mathrm{~Hz}, 2 \mathrm{H}), 10.37(\mathrm{~s}, 2 \mathrm{H}) \text {, and } 10.38(\mathrm{~s}, 2 \mathrm{H})\end{array}$ \\
\hline PPS (13) & $3366,3281,2985,2433,1663,1593,1138$, and 1043 & $\begin{array}{c}3.99(\mathrm{~s}, 4 \mathrm{H}), 7.08(\mathrm{dd}, J=2.5,7.5 \mathrm{~Hz}, 2 \mathrm{H}), 7.41-7.43(\mathrm{~m}, 3 \mathrm{H}) \\
7.45-7.47(\mathrm{~m}, 2 \mathrm{H}), 7.68(\mathrm{~d}, J=9 \mathrm{~Hz}, 2 \mathrm{H}), 7.73(\mathrm{~d}, J=7.5 \mathrm{~Hz}, \\
2 \mathrm{H}), 7.78-7.79(\mathrm{~m}, 2 \mathrm{H}), 7.95-7.98(\mathrm{~m}, 2 \mathrm{H}), 8.86(\mathrm{~s}, 1 \mathrm{H}), 8.92(\mathrm{~s}, \\
1 \mathrm{H}), 10.92(\mathrm{~s}, 2 \mathrm{H}) \text {, and } 10.93(\mathrm{~s}, 2 \mathrm{H})\end{array}$ \\
\hline
\end{tabular}

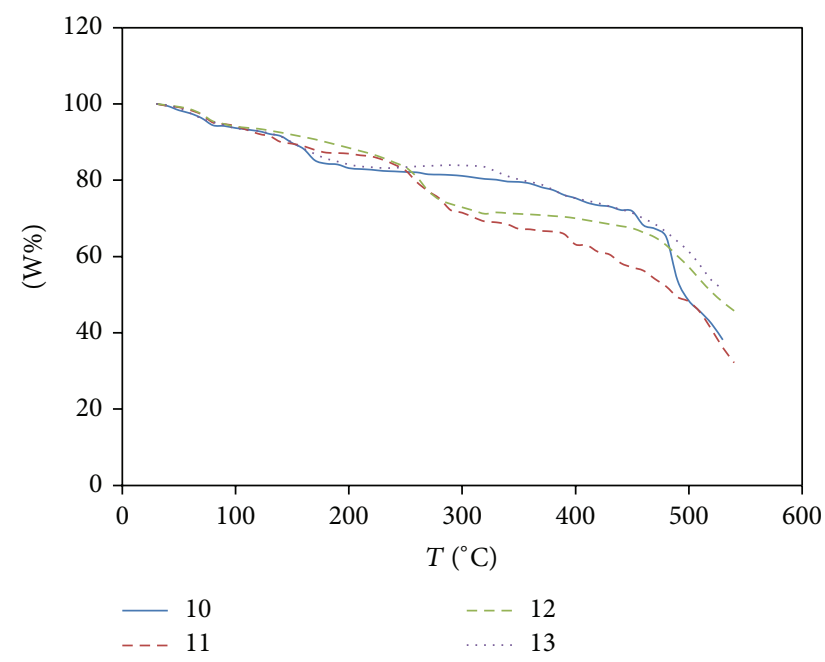

Figure 3: TGA of polyamides (10-13).

TABLE 3: Thermal properties of polyamides.

\begin{tabular}{lcccc}
\hline Polymer & $T_{g}\left({ }^{\circ} \mathrm{C}\right)$ & $T_{10}{ }^{\mathrm{a}}\left({ }^{\circ} \mathrm{C}\right)$ & $T_{50}{ }^{\mathrm{b}}\left({ }^{\circ} \mathrm{C}\right)$ & Char yields $^{\mathrm{c}} 550^{\circ} \mathrm{C}(\%)$ \\
\hline PPY (10) & 234 & 144 & 495 & 38 \\
PPH (11) & 223 & 137 & 483 & 32 \\
PMS (12) & 268 & 173 & 512 & 43 \\
PPS (13) & 295 & 159 & 523 & 47 \\
\hline
\end{tabular}

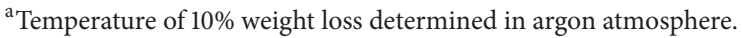

${ }^{\mathrm{b}}$ Temperature of $50 \%$ weight loss determined in argon atmosphere.

${ }^{\mathrm{c}} \mathrm{Char}$ yield calculated as the percentage of solid residue after heating from room temperature to $550^{\circ} \mathrm{C}$ under argon.

then increase the crystallinity and close packing. On the other hand, sulfone units in the aromatic diamines reduce the flexibility and increased close packing and crystallinity. According to the above discussion, therefore, the solubility of polyamides was affected by the several variables and, significantly, the structural variations in diacid monomer (4) and aromatic diamine components can be considered.

The surface morphology of polymers has been studied by scanning electron microscopy using their SEM images

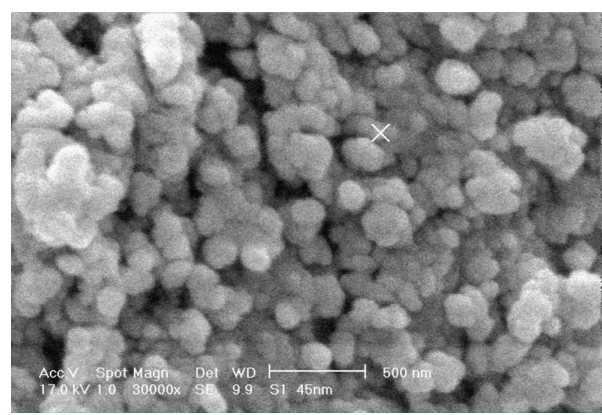

FIGURE 4: SEM image of polyamide PPY (10).

TABLE 4: The solubility of polyamides.

\begin{tabular}{lcccccc}
\hline Polymer & NMP & DMAc & DMF & DMSO & m-Cresol & THF \\
\hline PPY (10) & ++ & ++ & ++ & ++ & \pm & + \\
PPH (11) & ++ & ++ & ++ & ++ & + & + \\
PMS (12) & ++ & ++ & ++ & ++ & - & - \\
PPS (13) & ++ & ++ & ++ & ++ & - & - \\
\hline
\end{tabular}

$(++)$ : soluble at room temperature; $(+)$ : soluble upon heating; $( \pm)$ : partially soluble.

${ }^{\mathrm{a}}$ Solubility measured at a polymer concentration of $0.05 \mathrm{~g} / \mathrm{mL}$.

(Figures 4, 5, 6, and 7). According to these images, 10 and 13 showed particle structure; also $\mathbf{1 1}$ and $\mathbf{1 2}$ showed amorphous structures.

\section{Conclusion}

In summary, we have synthesized and characterized a new set of polyamides based on the pyridine and thiosalicylic acid subunits. They were successfully obtained through the direct polycondensation reaction of 2,6-bis(2-thio-2-(4phenylcarboxy)-1-oxo)pyridine with various diamines via Yamazaki method under microwave irradiation (MW). The solubility and thermal stability polymers are high. This may be due to the presence of pyridine and methylene groups in the presence of the tetrahedral sulfide functional group. The presence of sulfone group in the diamine subunit increased 


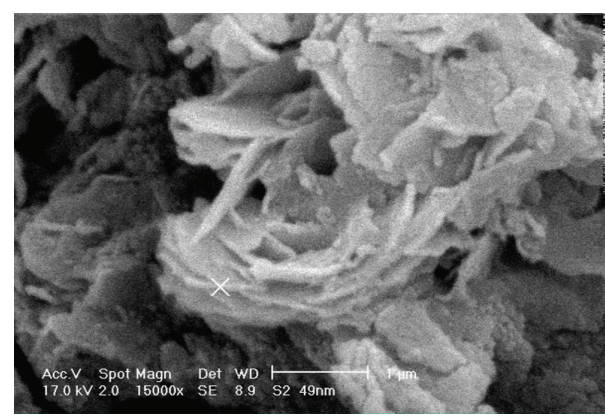

FIgURE 5: SEM image of polyamide PPH (11).

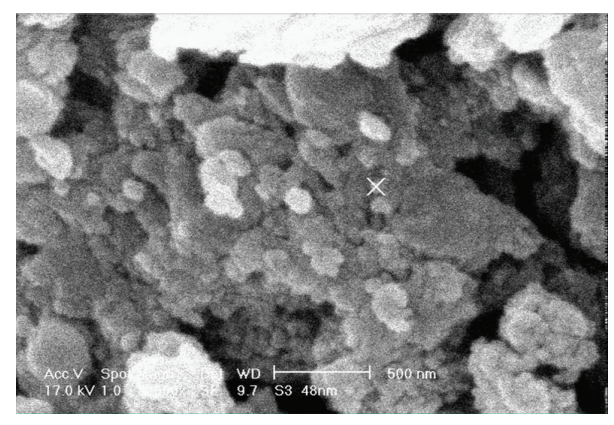

Figure 6: SEM image of polyamide PMS (12).

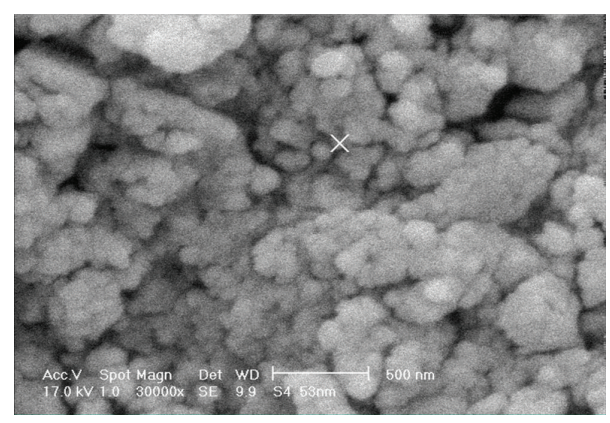

FIgURE 7: SEM image of polyamide PPS (13).

glass transition temperature, and, as a result, polymers with higher symmetric and rigid structures in diamine subunit and, as a result in overall, polymer backbone showed the highest thermal stability. Thus, we afforded polyamides with improved solubility and high heat resistance. The study of surface morphology of polyamides showed particle and amorphous structures.

\section{Conflict of Interests}

The authors declare that there is no conflict of interests regarding the publication of this paper.

\section{References}

[1] S. Jamshidi, H. Yeganeh, and S. Mehdipour-Ataei, "Preparation and properties of one-pack polybenzoxazine-modified polyurethanes with improved thermal stability and electrical insulating properties," Polymer International, vol. 60, no. 1, pp. 126-135, 2011.

[2] K. Faghihi, M. Ashouri, and A. Feyzi, "Synthesis and characterization of new polyimide/organoclay nanocomposites containing benzophenone moieties in the main chain," Journal of the Mexican Chemical Society, vol. 57, no. 2, pp. 133-136, 2013.

[3] D. J. Yoo, S. H. Hyun, A. R. Kim, G. G. Kumar, and K. S. Nahm, "Novel sulfonated poly(arylene biphenylsulfone ether) copolymers containing bisphenylsulfonyl biphenyl moiety: structural, thermal, electrochemical and morphological characteristics," Polymer International, vol. 60, no. 1, pp. 85-92, 2011.

[4] A.-H. M. El-Aassar, "Polyamide thin film composite membranes using interfacial polymerization: synthesis, characterization and reverse osmosis performance for water desalination," Australian Journal of Basic and Applied Sciences, vol. 6, no. 6, pp. 382-391, 2012.

[5] X. Yu, X. Zhao, C. Liu et al., "Synthesis and properties of thermoplastic polyimides with ether and ketone moieties," Journal of Polymer Science A: Polymer Chemistry, vol. 48, no. 13, pp. 2878-2884, 2010.

[6] D. Chao, L. He, E. B. Berda, S. Wang, X. Jia, and C. Wang, "Multifunctional hyperbranched polyamide: synthesis and properties," Polymer, vol. 54, no. 13, pp. 3223-3229, 2013.

[7] M. Ghaemy and M. Barghamadi, "Fluorene-ring-containing diamine and resultant soluble thermally stable polyamides," Journal of Applied Polymer Science, vol. 110, no. 3, pp. 1730-1738, 2008.

[8] S. H. Hsiao, C. W. Chen, and G. S. Liou, "Novel aromatic polyamides bearing pendent diphenylamino or carbazolyl groups," Journal of Polymer Science A: Polymer Chemistry, vol. 42, no. 13, pp. 3302-3313, 2004.

[9] W. Xie, G. M. Geise, B. D. Freeman, H.-S. Lee, G. Byun, and J. E. McGrath, "Polyamide interfacial composite membranes prepared $m$-phenylenediamine, trimesoyl chloride and a new disulfonateddiamine," Journal of Membrane Science, vol. 403404, pp. 152-161, 2012.

[10] R. R. Pal, P. S. Patil, M. M. Salunkhe, N. N. Maldar, and P. P. Wadgaonkar, "Synthesis, characterization and constitutional isomerism study of new aromatic polyamides containing pendant groups based on asymmetrically substituted metaphenylene diamines," European Polymer Journal, vol. 45, no. 3, pp. 953-959, 2009.

[11] M. Ghaemy and M. Barghamadi, "Synthesis and characterization of novel photoactive polyamide derived from substituted fluorene by copper (I) catalyst," Journal of Applied Polymer Science, vol. 114, no. 6, pp. 3464-3471, 2009.

[12] P. Blondin, J. Bouchard, S. Beapre, M. Belletete, G. Durocher, and M. Leclerc, "Molecular design and characterization of chromic polyfluorene derivatives," Macromolecules, vol. 33, no. 16, pp. 5874-5879, 2000.

[13] S.-H. Chen, C.-S. Shiau, L.-R. Tsai, and Y. Chen, "Poly(9,9dihexylfluorene) derivatives containing electron-transporting aromatic triazole segments: synthesis, optical and electrochemical properties," Polymer, vol. 47, no. 26, pp. 8436-8443, 2006.

[14] D.-J. Liaw and W.-H. Chen, "Synthesis and characterization of new soluble cardo poly(amide-imide)s derived from 2,2bis[4-(4-trimellitimidophenoxy)phenyl]norbornane," Polymer, vol. 44, no. 14, pp. 3865-3870, 2003.

[15] H.-J. Yen and G.-S. Liou, "Novel thermally stable triarylaminecontaining aromatic polyamides bearing anthrylamine chromophores for highly efficient green-light-emitting materials," 
Journal of Polymer Science A: Polymer Chemistry, vol. 46, no. 22, pp. 7354-7368, 2008.

[16] M. Ghaemy and R. Alizadeh, "Synthesis, characterization and photophysical properties of organosoluble and thermally stable polyamides containing pendent $\mathrm{N}$-carbazole group," Reactive and Functional Polymers, vol. 71, no. 4, pp. 425-432, 2011.

[17] Y.-L. Liu and S.-H. Tsai, "Synthesis and properties of new organosoluble aromatic polyamides with cyclic bulky groups containing phosphorus," Polymer, vol. 43, no. 21, pp. 5757-5762, 2002.

[18] E. Rostami, "Synthesis and characterization of new polyamides containing pyridine thioetherunits in the main chain under microwave irradiation (MW) and their nanostructure," International Journal of Polymeric Materials and Polymeric Biomaterials, vol. 62, no. 3, pp. 175-180, 2013.

[19] R. Gedye, F. Smith, K. Westaway et al., "The use of microwave ovens for rapid organic synthesis," Tetrahedron Letters, vol. 27, no. 3, pp. 279-282, 1986.

[20] P. Lidström and J. P. Tierney, Eds., Microwave-Assisted Organic Synthesis, Blackwell, Oxford, UK, 2005.

[21] B. A. Roberts and C. R. Strauss, "Toward rapid, "green", predictable microwave-assisted synthesis," Accounts of Chemical Research, vol. 38, no. 8, pp. 653-661, 2005.

[22] D. D. Artman, A. W. Grubbs, and R. M. Williams, "Concise, asymmetric, stereocontrolled total synthesis of stephacidins A, B and notoamide B," Journal of the American Chemical Society, vol. 129, no. 19, pp. 6336-6342, 2007.

[23] C. O. Kappe and D. Dallinger, "The impact of microwave synthesis on drug discovery," Nature Reviews Drug Discovery, vol. 5, no. 1, pp. 51-63, 2006.

[24] R. Hoogenboom and U. S. Schubert, "Microwave-assisted polymer synthesis: recent developments in a rapidly expanding field of research," Macromolecular Rapid Communications, vol. 28, no. 4, pp. 368-386, 2007.

[25] J. Perelaer, B.-J. de Gans, and U. S. Schubert, "Ink-jet printing and microwave sintering of conductive silver tracks," Advanced Materials, vol. 18, no. 16, pp. 2101-2104, 2006.

[26] A. Burya, O. Kuznetsova, A. Konchits, and A. Redchuk, "The influence of nanocluster carbon materials on the structure and properties of polyamide nanocomposites," Materials Science Forum, vol. 674, no. 2, pp. 189-193, 2011.

[27] J. M. Collins and N. E. Leadbeater, "Microwave energy: a versatile tool for the biosciences," Organic \& Biomolecular Chemistry, vol. 5, no. 8, pp. 1141-1150, 2007.

[28] T. N. Glasnov and C. O. Kappe, "Microwave-assisted synthesis under continuous-flow conditions," Macromolecular Rapid Communications, vol. 28, no. 4, pp. 395-410, 2007.

[29] S. Mallakpour and M. Taghavi, "Molten tetrabutylammonium bromide as eco-friendly media for the synthesis of optically active and thermal stable polyamides under microwave irradiation," Polymer Journal, vol. 40, no. 11, pp. 1049-1059, 2008.

[30] S. Mallakpour and Z. Rafiee, "Application of microwave-assisted reactions in step-growth polymerization: a review," Iranian Polymer Journal, vol. 17, no. 12, pp. 907-935, 2008.

[31] H. N. Isfahani, K. Faghihi, M. Hajibeygi, and M. Bokaei, "New optically active poly (amide-imide)s from $N, N^{\prime}$ - (bicycle $[2,2,2]$ oct-7-ene-2,3,5,6-tetracarboxylic) bis-1-phenyl alanine and aromatic diamines: synthesis and characterization," Polymer Bulletin, vol. 64, no. 7, pp. 633-646, 2010.

[32] S. Sinnwell and H. Ritter, "Recent advances in microwaveassisted polymer synthesis," Australian Journal of Chemistry, vol. 60 , no. 10, pp. 729-743, 2007.
[33] A. Banihashemi, H. Hazarkhani, and A. Abdolmaleki, "Efficient and rapid synthesis of polyureas and polythioureas from the reaction of urea and thiourea with diamines under microwave irradiation," Journal of Polymer Science A: Polymer Chemistry, vol. 42, no. 9, pp. 2106-2111, 2004.

[34] C. Holtze, M. Antonietti, and K. Tauer, "Ultrafast conversion and molecular weight control through temperature programming in microwave-induced miniemulsion polymerization," Macromolecules, vol. 39, no. 17, pp. 5720-5728, 2006.

[35] K. R. Reddy, A. V. Raghu, H. M. Jeong, and S. Siddaramaiah, "Synthesis and characterization of pyridine-based polyurethanes," Designed Monomers and Polymers, vol. 12, no. 2, pp. 109-118, 2009.

[36] N. I. Abdel-Sayed, "Novel synthesis of new symmetrical bis-heterocyclic compounds: synthesis of bis-thiazolo, bispyrazolo-, bis-benzotriazolo, bis-indolo- and bis-pyrazolyl thiazolo-2,6-diamino pyridine derivatives," Bulgarian Chemical Communications, vol. 42, no. 1, pp. 20-26, 2010. 

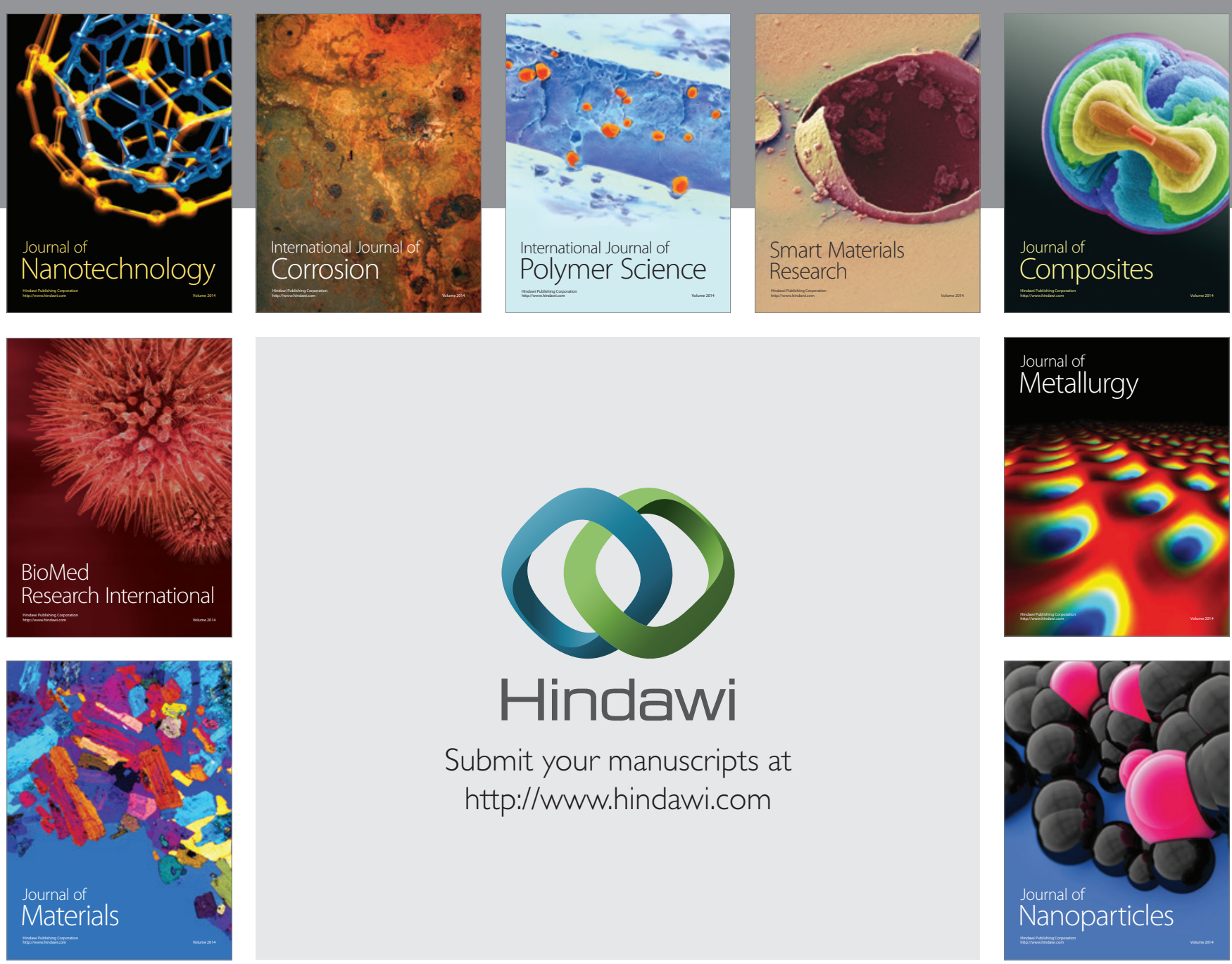

Submit your manuscripts at http://www.hindawi.com
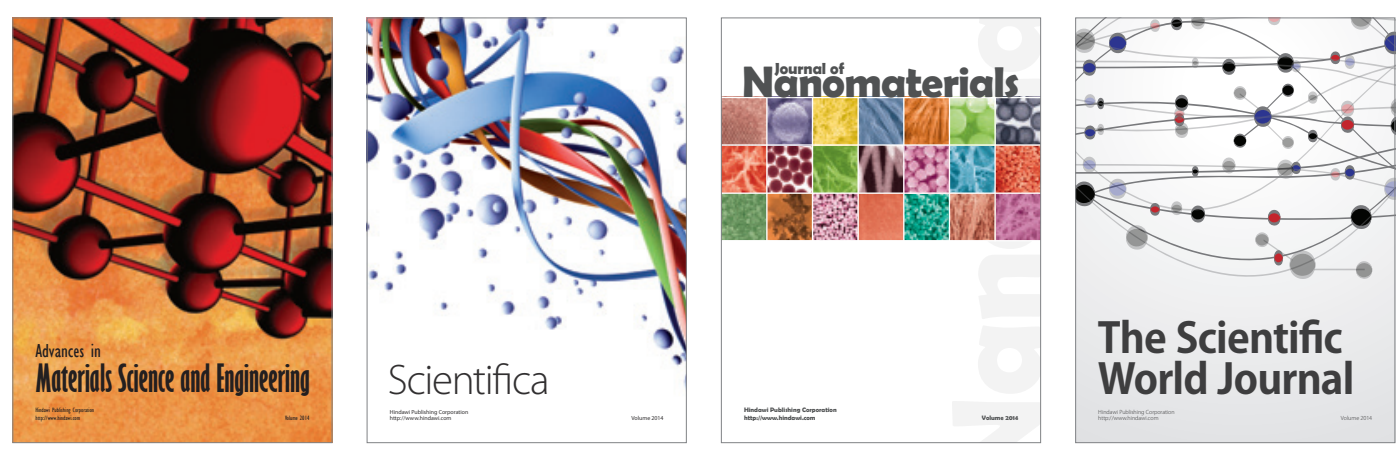

\section{The Scientific World Journal}
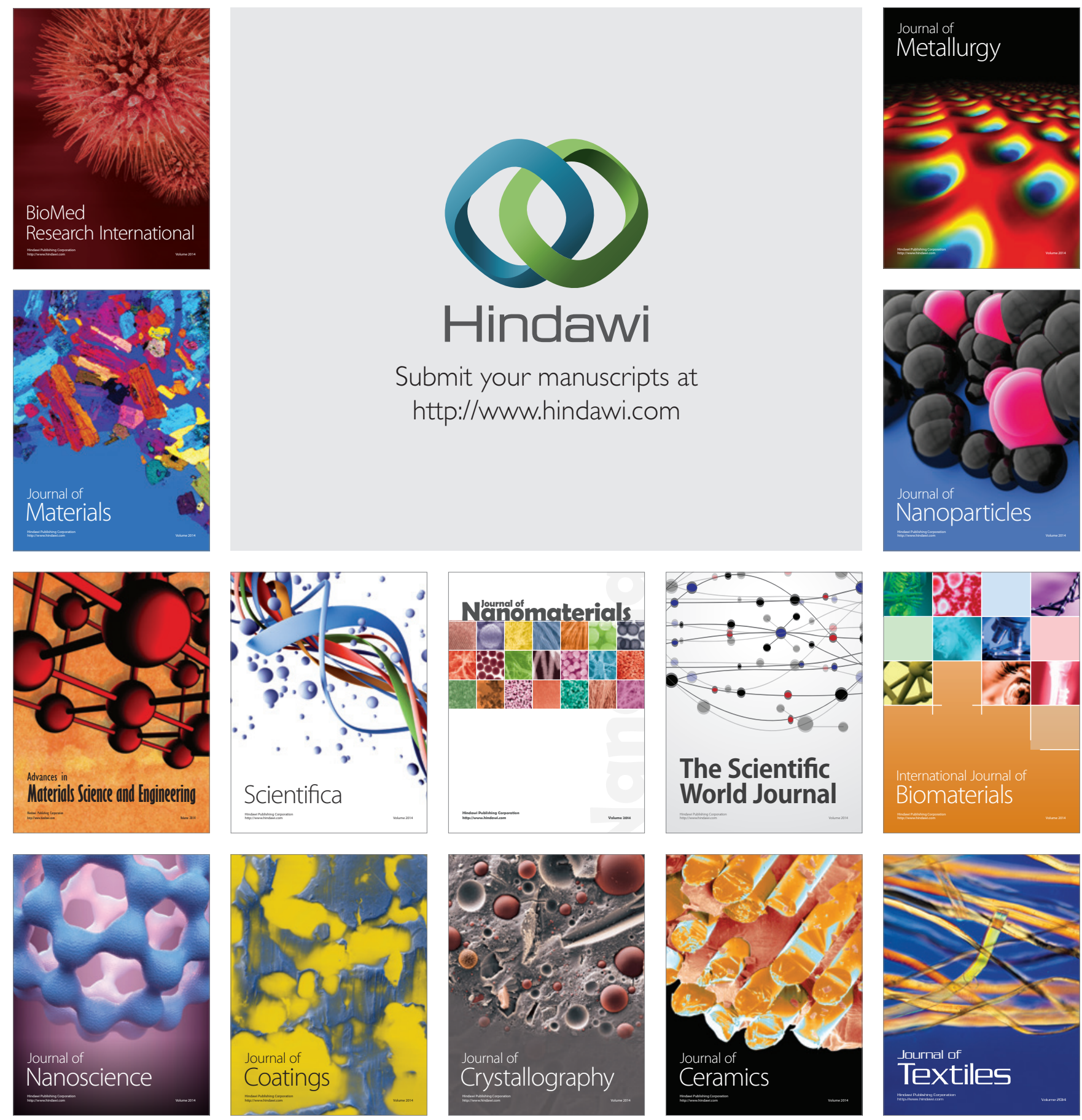